\title{
Distribution of Trauma Care Facilities in Oman in Relation to High-Incidence Road Traffic Injury Sites Pilot study
}

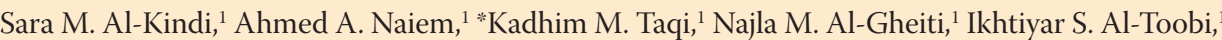
Nasra Q. Al-Busaidi, ${ }^{1}$ Ahmed Z. Al-Harthy, ${ }^{1}$ Alaa M. Taqi, ${ }^{2}$ Sharif A. Ba-Alawi, ${ }^{2}$ Hani A. Al-Qadhi ${ }^{3}$

$$
\begin{aligned}
& \text { توزيع مرافق الرعاية الصحية للمصابين في عمان فيما يتعلق بمواقع إصابات } \\
& \text { حوادث المرور المرتغعة } \\
& \text { دراسة تجريبية }
\end{aligned}
$$

سارة الكندية، أحمد أشرف نعيم، كاظم مصطفى تقي، نجلاء الغيثية، اختيار التوبية، نصرة قاسم البوسعيدية،

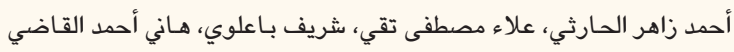

ABSTRACT: Objectives: Road traffic injuries (RTIs) are considered a major public health problem worldwide. In Oman, high numbers of RTIs and RTI-related deaths are frequently registered. This study aimed to evaluate the distribution of trauma care facilities in Oman with regards to their proximity to RTI-prevalent areas. Methods: This descriptive pilot study analysed RTI data recorded in the national Royal Oman Police registry from January to December 2014. The distribution of trauma care facilities was analysed by calculating distances between areas of peak RTI incidence and the closest trauma centre using Google Earth and Google Maps software (Google Inc., Googleplex, Mountain View, California, USA). Results: A total of 32 trauma care facilities were identified. Four facilities (12.5\%) were categorised as class V trauma centres. Of the facilities in Muscat, 42.9\% were ranked as class IV or V. There were no class IV or V facilities in Musandam, Al-Wusta or Al-Buraimi. General surgery, orthopaedic surgery and neurosurgery services were available in $68.8 \%, 59.3 \%$ and $12.5 \%$ of the centres, respectively. Emergency services were available in $75.0 \%$ of the facilities. Intensive care units were available in 11 facilities, with four located in Muscat. The mean distance between a RTI hotspot and the nearest trauma care facility was 34.7 $\mathrm{km}$; however, the mean distance to the nearest class IV or V facility was $83.3 \mathrm{~km}$. Conclusion: The distribution and quality of trauma care facilities in Oman needs modification. It is recommended that certain centres upgrade their levels of trauma care in order to reduce RTI-associated morbidity and mortality in Oman.

Keywords: Traffic Accidents; Motor Vehicles; Trauma Centers; Public Health; Emergency Medical Services; Oman.

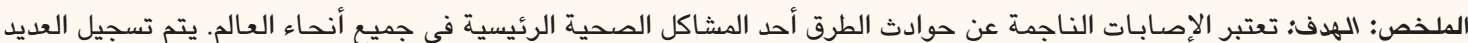

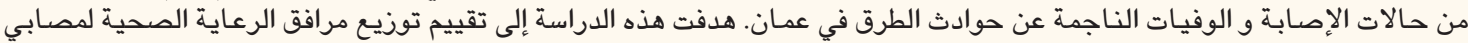

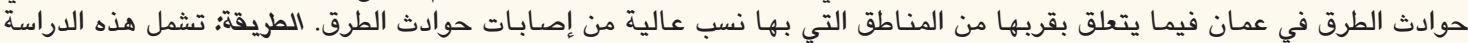

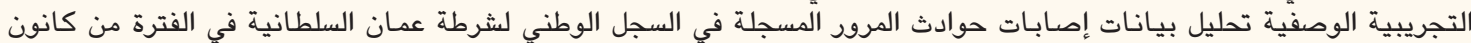

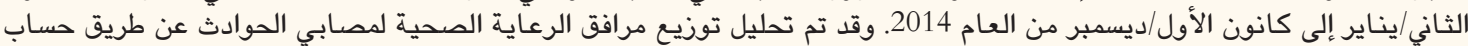

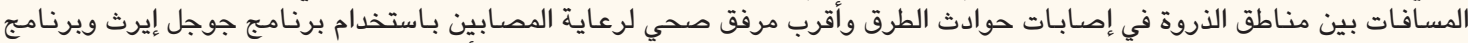

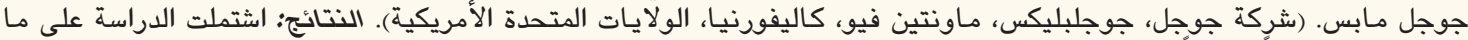

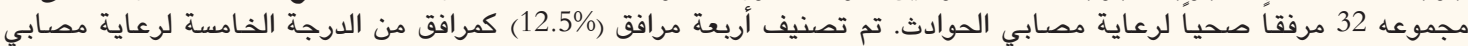

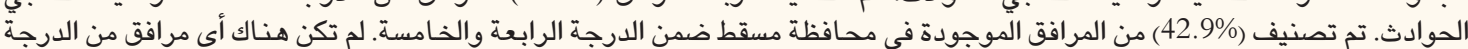

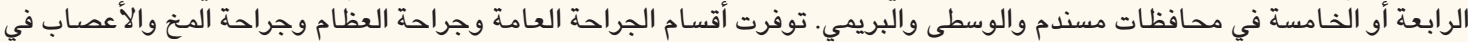

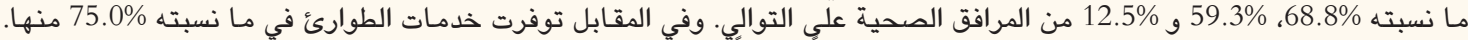

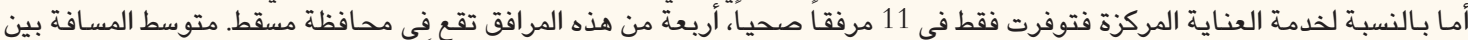

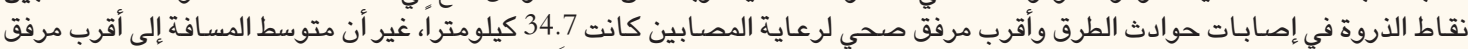

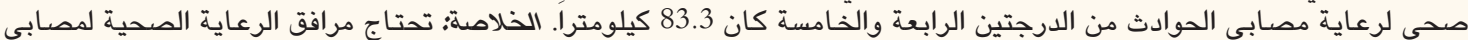

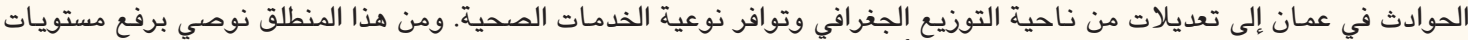

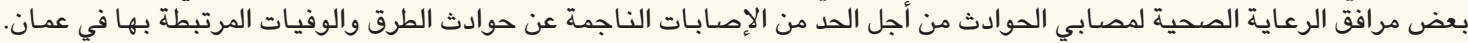

$$
\text { الكلمات المفتاحية: حوادث الطرق؛ السيارات؛ مرافق الرعاية الصحية لمصابي الحوادث؛ الصحة العامة؛ خدمة الإسعاف الطبي؛ عمان. }
$$




\section{AdVANCES IN KNOWLEDGE}

The current study found that the mean distance between a road traffic injury (RTI) hotspot and the nearest trauma care facility in Oman was $34.7 \mathrm{~km}$; moreover, RTI hotspots were a mean distance of $83.3 \mathrm{~km}$ away from the nearest class IV or V facility.

The majority of class IV and V trauma care facilities in Oman were found to be located in Muscat, with such facilities entirely lacking in certain other governorates.

\section{Application to Patient Care}

The findings of the current study suggest that the distribution and quality of trauma care facilities in Oman is inadequate. Upgrading existing trauma care facilities in certain locations and building new trauma centres closer to known RTI hotspots may help to decrease morbidity and mortality associated with RTIs.

\section{$\mathrm{T}$} RAUMA REPRESENTS A MAJOR YET PREVENTABLE health burden worldwide; in particular, the World Health Organization (WHO) identifies road traffic injuries (RTI) to be a major public health problem, with over a million people killed due to RTIs annually. ${ }^{1}$ By 2020, this number is expected to increase by $65 \%$ and $80 \%$ in higher- and lower-income countries, respectively. ${ }^{1,2}$ A major factor in preventing RTI-related deaths is the rapid transfer of victims to a trauma care centre within 60 minutes of the incident, also known as the "golden hour".-5 Therefore, ensuring the regional availability of trauma care facilities can be tremendously beneficial. Many methods have been suggested to identify shortcomings in national trauma care systems and their structure in order to improve survival for trauma victims, including estimating the distance between high-incidence RTI sites and trauma care centres, which can help in the planning of future trauma centres and when improving the existing infrastructure. ${ }^{4,6}$

In Oman, RTIs account for high mortality and morbidity; in 2013, the Ministry of Health (MOH) reported 646 RTI-related deaths on arrival (DOAs) to hospitals or prior to admission. ${ }^{7}$ In addition, $68.4 \%$ of inpatient deaths at $\mathrm{MOH}$-affiliated hospitals were attributed to RTIs in 2013, with more than twothirds of the deaths occurring among individuals aged 15-44 years old.? Geographically, Oman is divided into 11 administrative governorates extending over an area of $309,500 \mathrm{~km}^{2}$, with each governorate subdivided into smaller wilayats [Figure 1]. The governorate with the highest population density is Muscat, the capital city; however, only $7.3 \%$ of RTI-related DOAs in 2013 were reported to have occurred in this region. ${ }^{7,8}$ In contrast, Al-Batinah North and Al-Dakhiliyah accounted for the highest number of DOAs (18.7\% each); these governorates have estimated populations of 772,590 and 336,651 individuals, respectively. The lowest number of DOAs was reported in Musandam (0.2\%), which has an estimated population of 31,425 individuals. ${ }^{7,8}$

According to the WHO, Oman is considered a high-income country with good death registration data. ${ }^{1}$ In 2010, the WHO reported 820 RTI-related deaths in Oman, with estimates of permanent disability set at $1.4 \%{ }^{1}$ To the best of the authors' knowledge, no study has yet evaluated the accessibility and quality of trauma care facilities in Oman with regards to known sites of RTIs. Therefore, the purpose of this pilot study was to evaluate the distribution of trauma centres in Oman and their proximity to RTI-prevalent areas in order to lay the groundwork for future analyses.

\section{Methods}

This descriptive pilot study was performed between January and December 2014. Existing healthcare facilities in Oman which provided care to trauma victims during this period as well as the number of victims presenting to different healthcare facilities by governorate were identified from multiple sources at the $\mathrm{MOH} .{ }^{7,9}$ Identified trauma centres were broadly

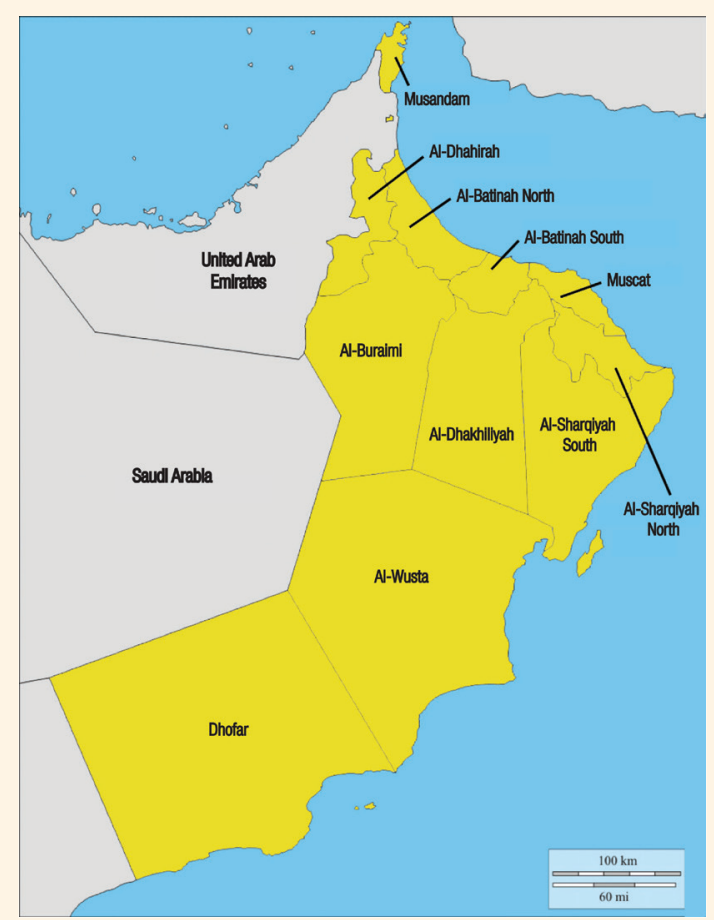

Figure 1: Geographical map of Oman showing the administrative division of governorates.

Map created using Scribble Maps software (52 Stairs Studio Inc., Windsor, Ontario, Canada). 
Table 1: Classification of trauma care facilities based on service availability

\begin{tabular}{lccccc} 
Class & \multicolumn{5}{c}{ Available services } \\
I & $\begin{array}{l}\text { General } \\
\text { surgery }\end{array}$ & CT & ICU & $\begin{array}{c}\text { Orthopaedic } \\
\text { surgery }\end{array}$ & $\begin{array}{c}\text { Neuro- } \\
\text { surgery }\end{array}$ \\
II & No & No & No & No & No \\
III & Yes & No & No & No & No \\
IV & Yes & Yes & Yes & No & No \\
V & Yes & Yes & Yes** & Yes* \\
CT & Yes & Yes & Yes & Yes \\
*ne or the other, but not both. & &
\end{tabular}

categorised based on the classifications of the American College of Surgeons Committee on Trauma (ACSCOT), which classifies trauma care facilities based on their capacity to treat trauma patients, the volume of cases they can accommodate and their educational and research commitments in the field of trauma. ${ }^{10}$ Unfortunately, it was not possible to utilise the exact ACSCOT classifications as certain prerequisites were not applicable to trauma care facilities in Oman. Instead, the trauma care facilities were similarly divided into five classes based on the provision of various surgical and medical services, with class $\mathrm{V}$ indicating the highest level of care offered and class I the lowest [Table 1].

Subsequently, data on all RTIs occurring in Oman during the study period were obtained from the Royal Oman Police registry, which keeps track of the geographical locations where RTIs occur and the overall number of RTIs which occur at certain RTIprevalent locations known as hotspots, where RTIs are known to have resulted in death or serious injury. Google Earth and Google Maps software interfaces (Google Inc., Googleplex, Mountain View, California, USA) were then used to obtain the coordinates of RTI sites and the closest trauma care facilities and to calculate distances between the two locations.

The results were displayed on maps created using Scribble Maps software (52 Stairs Studio Inc., Windsor, Ontario, Canada). Data were analysed using the Statistical Package for the Social Sciences (SPSS), Version 23.0 (IBM Corp., Armonk, New York, USA). Administrative approval was obtained from all of the concerned authorities for use of the secondary data utilised in this study.

Table 2: Distribution of trauma care facilities in Oman according to governorate, class and distance to road traffic injury hotspots $(\mathrm{N}=32)$

\begin{tabular}{|c|c|c|c|c|c|}
\hline Governorate & $\begin{array}{l}\text { Population density in } \\
\text { people } / \mathbf{k m}^{2}\end{array}$ & \multicolumn{2}{|c|}{$\begin{array}{c}\text { Number of } \\
\text { facilities per class }\end{array}$} & $\begin{array}{c}\text { Mean distance } \\
\text { from RTI hotspot } \\
\text { to nearest facility } \\
\text { in } \mathbf{k m}\end{array}$ & $\begin{array}{l}\text { Mean distance from } \\
\text { RTI hotspot to nearest } \\
\text { class IV or V facility } \\
\text { in km }\end{array}$ \\
\hline Muscat & 300.8 & $\begin{array}{l}\text { Class V } \\
\text { Class IV } \\
\text { Class III } \\
\text { Class I }\end{array}$ & $\begin{array}{l}2 \\
1 \\
1 \\
3\end{array}$ & 4.1 & 22.4 \\
\hline Al-Batinah South & 80.5 & $\begin{array}{l}\text { Class IV } \\
\text { Class I }\end{array}$ & $\begin{array}{l}1 \\
1\end{array}$ & 35.9 & 35.9 \\
\hline Al-Batinah North & 83.0 & Class V & 1 & 30.0 & 30.0 \\
\hline Musandam & 21.4 & $\begin{array}{l}\text { Class III } \\
\text { Class II }\end{array}$ & $\begin{array}{l}1 \\
1\end{array}$ & 4.7 & 304.0 \\
\hline Al-Sharqiyah South & 22.2 & $\begin{array}{l}\text { Class IV } \\
\text { Class II } \\
\text { Class I }\end{array}$ & $\begin{array}{l}1 \\
2 \\
1\end{array}$ & 5.7 & 5.7 \\
\hline Al-Sharqiyah North & 10.0 & $\begin{array}{l}\text { Class IV } \\
\text { Class III } \\
\text { Class I }\end{array}$ & $\begin{array}{l}1 \\
1 \\
4\end{array}$ & 4.8 & 4.8 \\
\hline Al-Buraimi & 12.4 & Class III & 1 & 39.6 & 85 \\
\hline Al-Dhahirah & 5.2 & Class IV & 1 & 9.0 & 9.0 \\
\hline Al-Dakhiliyah & 12.6 & $\begin{array}{l}\text { Class IV } \\
\text { Class II } \\
\text { Class I }\end{array}$ & $\begin{array}{l}1 \\
3 \\
1\end{array}$ & 3.0 & 3.0 \\
\hline Al-Wusta & 0.5 & Class I & 1 & 3.5 & 374.0 \\
\hline Dhofar & 3.8 & $\begin{array}{l}\text { Class V } \\
\text { Class III }\end{array}$ & $\begin{array}{l}1 \\
1\end{array}$ & 3.7 & 14.9 \\
\hline
\end{tabular}

$R T I=$ road traffic injuries. 


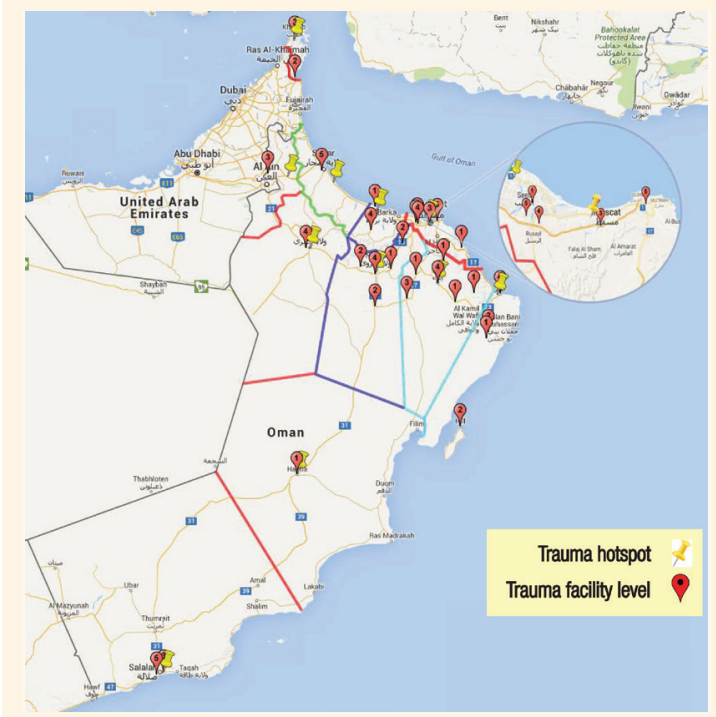

Figure 2: Distribution map of available trauma care facilities in Oman in relation to road traffic injury hotspots $(\mathrm{N}=32)$.

Map created using Scribble Maps software (52 Stairs Studio Inc., Windsor, Ontario, Canada) and Google Maps software interface (Google Inc., Googleplex, Mountain View, California, USA).

\section{Results}

A total of 32 trauma care facilities were identified, of which 11 (34.4\%) were class I centres. Only four centres (12.5\%) were categorised as class V facilities; these were located in Muscat, Al-Batinah North and Dhofar. Muscat had the largest overall number of trauma care facilities, with $42.9 \%$ of its facilities ranked as class IV or V. In contrast, Musandam, Al-Wusta and Al-Buraimi lacked class IV or V facilities entirely. The overall mean distance between RTI hotspots and the nearest trauma care facility was $34.7 \mathrm{~km}$, while the mean distance to a class IV or V trauma facility was $83.3 \mathrm{~km}$. The governorate with the shortest mean distance between RTI hotspots and class IV or V centres was Al-Dakhiliyah (3.0 km), whereas Al-Wusta
$(374.0 \mathrm{~km})$ and Musandam $(304.0 \mathrm{~km})$ had the greatest mean distances [Table 2]. Mapping the distribution of RTI hotspots and available trauma care facilities showed a dense clustering of trauma centres around Muscat in comparison to other governorates [Figure 2].

A total of $22(68.8 \%)$ and $24(75.0 \%)$ of the trauma facilities had general surgery and emergency services, respectively. Neurosurgery and orthopaedic surgery services were available in four (12.5\%) and 18 (59.3\%) centres, respectively. Ventilation support was only available in 15 facilities (46.9\%). General surgery services were available in all governorates apart from Al-Wusta, which had no special services available at all; however, neurosurgery services were only available in three governorates (Muscat, Al-Batinah North and Dhofar). In total, only 11 centres (68.8\%) had an intensive care unit (ICU), of which four were located in Muscat (12.5\%), while Al-Sharqiyah South and Al-Wusta completely lacked any type of ICU services [Figure 3].

\section{Discussion}

In this pilot study, the application of non-ACSCOT classifications to Omani trauma care facilities enabled the identification of centres which lacked definitive trauma services but nevertheless contributed to trauma management by allowing the early stabilisation and transfer of the patient to other centres. In Oman, although major trauma centres have both surgeons and emergency physicians who can provide resuscitation and management procedures, certain strict requirements for certification as a trauma centre by the American College of Surgeons are not met (e.g. the admission of $\geq 1,200$ trauma cases annually). ${ }^{10}$ As such, a broader classification was devised based on the availability of those specialty services most commonly required when managing trauma cases.

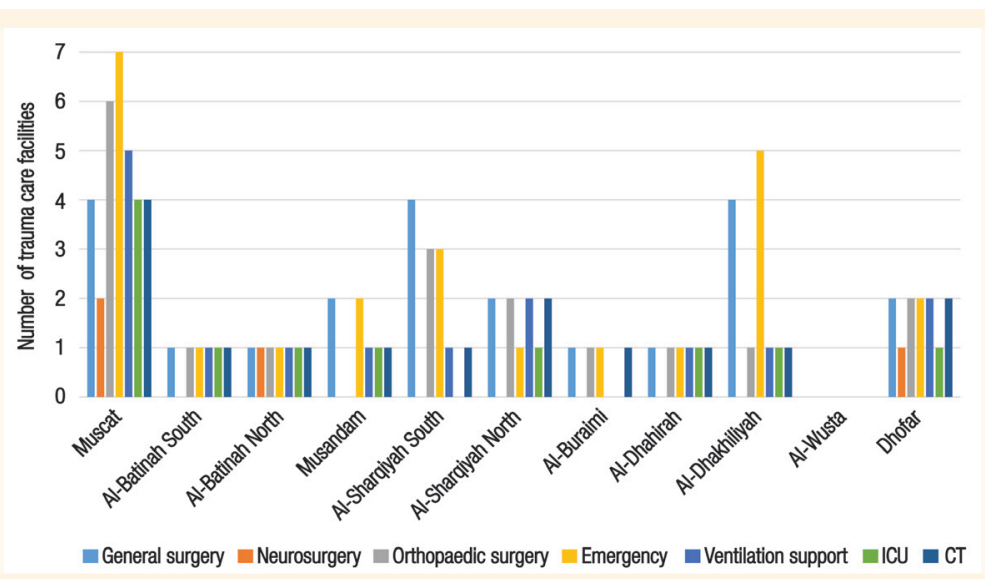

Figure 3: Availability of various services in trauma care facilities in Oman according to governorate $(\mathrm{N}=32)$. $I C U=$ intensive care unit CT = computed tomography. 
Trauma usually involves multiple systems, particularly the nervous and musculoskeletal systems. Traumatic brain injuries are the most common cause of death in trauma cases, highlighting the necessity of providing neurosurgery services. ${ }^{11}$ Musculoskeletal injuries are also frequent and most trauma causes therefore require consultation with an orthopaedic surgeon. ${ }^{2}$ Additionally, a dedicated ICU facility is integral in reducing preventable deaths. ${ }^{12}$ According to the American College of Surgeons, computed tomography imaging modalities are also deemed mandatory for large trauma centres; moreover, a general surgeon-either as a leader or member of the trauma team-should represent the cornerstone of a trauma system. ${ }^{10}$ Finally, the emergency department is usually the site of the initial encounter between the trauma team and victim; thus, the involvement of emergency physicians is vital. ${ }^{10,13}$

According to the findings of the current pilot study, the distribution of high-class trauma care facilities in Oman seems to correspond with population density. Muscat appears to be the best-equipped governorate in Oman for the management of trauma cases, particularly those that might require specialised services like general surgery, orthopaedic surgery or neurosurgery; this is fitting in view of its position as the most densely-populated governorate in Oman. ${ }^{8}$ On average, RTI victims in Muscat were only $4.1 \mathrm{~km}$ away from the closest trauma facility where initial resuscitation and preparation for transfer could take place; moreover, definite management at a IV or $\mathrm{V}$ trauma care facility, of which $27.3 \%$ were based in Muscat, was also highly accessible at a mean distance of $22.4 \mathrm{~km}$ away.

Other relatively densely-populated governorates such as Al-Batinah North and Al-Batinah South also had facilities where initial trauma care could be delivered; in addition, definitive care at a VI or $\mathrm{V}$ trauma centre was usually available within $36 \mathrm{~km}$. This is particularly important as Al-Batinah North has one of the highest numbers of RTI-related DOAs in the country. ${ }^{7}$ Al-Dakhiliyah, which has a similarly high level of RTI-related DOAs, has a lower population density but was found to have both initial management facilities and transfer capabilities to a high-level facility within $3.0 \mathrm{~km}$ of RTI hotspots. ${ }^{7,8}$ Although this was the shortest mean hotspot-to-facility distance recorded in the current study, the governorate nevertheless lacked specialised neurosurgery services, which therefore necessitates the transfer of trauma cases involving head injuries to other governorates.

As the least densely populated governorate, Al-Wusta was correspondingly found in the present study to lack any kind of high-level trauma facilities. ${ }^{8}$
Although initial management and resuscitation was on average accessible within $3.5 \mathrm{~km}$ of an RTI hotspot, definitive trauma care was over $370 \mathrm{~km}$ away, in the separate governorate of Al-Dakhiliyah. As with Al-Wusta, trauma cases in Musandam had to be transported an average of $304 \mathrm{~km}$ away to North Al-Batinah for definitive care. It is therefore clear that both air and land transportation infrastructure constitute an important part of the trauma system in Oman due to the potentially lengthy distances between known RTI hotspots and definitive trauma care facilities. As such, certain regions in Oman need to upgrade their available trauma care facilities and potentially build entirely new trauma facilities so as to reduce RTI-associated morbidity and mortality in the country.

To the best of the author's knowledge, this pilot study is the first of its kind to evaluate the accessibility of trauma care health facilities in Oman in relation to known RTI-prevalent sites, with most existing studies targeting preventative aspects or focusing purely on the management of trauma cases. However, this study is not without its limitations and could not fully address the relationship between RTI sites and trauma care facilities. Given that Oman has no nationwide trauma registry, multiple variables could not be included, including modifiable factors associated with morbidity and mortality and data related to pre- and in-hospital management.

\section{Conclusion}

The findings of this pilot study indicate that certain areas in Oman need to upgrade available trauma care facilities or build entirely new trauma centres. This may help to improve identified gaps in the existing trauma care infrastructure and reduce RTI-associated morbidity and mortality in the country.

\section{CONFLICT OF INTEREST}

The authors declare no conflicts of interest.

\section{FUNDING}

No funding was received for this study.

\section{References}

1. World Health Organization. Global status report on road safety 2013: Supporting a decade of action. From: www.who. int/violence_injury_prevention/road_safety_status/2013/en/ Accessed: Jun 2017.

2. World Health Organization. World report on road traffic injury prevention. From: whqlibdoc.who.int/publications/ 2004/9241562609.pdf Accessed: Jun 2017. 
3. Sampalis JS, Lavoie A, Williams JI, Mulder DS, Kalina M. Impact of on-site care, prehospital time, and level of in-hospital care on survival in severely injured patients. J Trauma 1993; $34: 252-61$.

4. Sampalis JS, Denis R, Lavoie A, Fréchette P, Boukas S, Nikolis A, et al. Trauma care regionalization: A process-outcome evaluation. J Trauma 1999; 46:565-81.

5. Blackwell TH, Kaufman JS. Response time effectiveness: Comparison of response time and survival in an urban emergency medical services system. Acad Emerg Med 2002; 9:288-95. doi: 10.1197/aemj.9.4.288.

6. Mohan HM, Mullan D, McDermott F, Whelan RJ, O'Donnell C, Winter DC. Saving lives, limbs and livelihoods: Considerations in restructuring a national trauma service. Ir J Med Sci 2015; 184:659-66. doi: 10.1007/s11845-014-1234-9.

7. Oman Ministry of Health. Annual Health Report 2013. From: www.moh.gov.om/en_US/web/statistics/annual-reports Accessed: Jun 2017.

8. Oman National Centre for Statistics and Information. Population. From: https://data.gov.om/search?query=Popul ation\&scope=datasets Accessed: Jun 2017.
9. Oman Ministry of Health. Health vision 2050: Health atlas. From: www.moh.gov.om/documents/16506/120542/Health+Atlas /4a611e16-cdb9-4596-9e67-3bd9e2c0126d Accessed: Jun 2017.

10. American College of Surgeons. Resources for optimal care of the injured patient 2014. From: www.facs.org/quality-programs /trauma/vrc/resources Accessed: Jun 2017.

11. Pfeifer R, Tarkin IS, Rocos B, Pape HC. Patterns of mortality and causes of death in polytrauma patients: Has anything changed? Injury 2009; 40:907-11. doi: 10.1016/j.injury.2009.05.006.

12. Nathens AB, Rivara FP, MacKenzie EJ, Maier RV, Wang J, Egleston B, et al. The impact of an intensivist-model ICU on trauma-related mortality. Ann Surg 2006; 244:545-54. doi: 10. 1097/01.sla.0000239005.26353.49.

13. Gerardo CJ, Glickman SW, Vaslef SN, Chandra A, Pietrobon R, Cairns CB. The rapid impact on mortality rates of a dedicated care team including trauma and emergency physicians at an academic medical center. J Emerg Med 2011; 40:586-91. doi: 10.1016/j.jemermed.2009.08.056. 